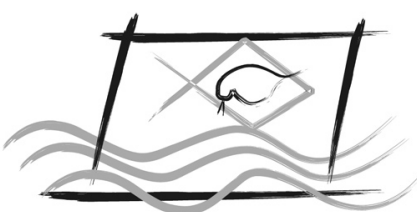

ECOTOX - BRASIL

\title{
Avaliação da toxicidade das águas do Rio Criciúma (Criciúma, Santa Catarina, Brasil), utilizando parâmetros físico-químicos e abordagens ecotoxicológicas
}

\author{
L.M. Bruchchen ${ }^{1}$; P.S. Silva ${ }^{1}$; F.Z. Silveira ${ }^{1}$; T.M. Defaveri ${ }^{1}$; C.T. Pich ${ }^{2} \&$ R. Geremias ${ }^{2 *}$ \\ ${ }^{1}$ Ciências Biológicas, UNESC, Criciúma, SC, Brasil. \\ ${ }^{2}$ Engenharia de Energia, UFSC, Araranguá, SC, Brasil.
}

(Received July 05, 2012; Accept October 03, 2013)

\begin{abstract}
Toxicity assessment on the waters from the Criciúma river (Criciúma, Santa Catarina, Brazil) using physicochemical parameters and ecotoxicological approaches - The Criciúma river (Criciúma, Santa Catarina, Brazil) receives daily potentially toxic waste generated by various human activities. This study aimed to evaluate the toxicity of water from the Criciúma river, using physico-chemical parameters and ecotoxicological approaches. River water samples were collected in three different stations. The values of $\mathrm{pH}, \mathrm{COD}, \mathrm{BOD}, \mathrm{DO}$ and hardness were determined. The following assays were performed: the acute toxicity in Daphnia magna, a test of inhibition of growth of roots in Allium cepa L. (onion), and genotoxicity (Comet test) in meristematic cells of Allium cepa L. and blood cells and liver tissue of fish Geophagus brasiliensis. The results indicated that the water collected in the central region showed increased values of COD, BOD and hardness and low values of DO. Acute toxicity was found for Daphnia magna, as well as significant inhibition of growth of the roots A. серa and genotoxic effects in A. cepa and G. brasiliensis exposed to waters from the central region. It was concluded that the waters of the Criciúma river are potentially toxic to biota exposed.
\end{abstract}

Keywords: Criciúma river (Criciúma, Santa Catarina, Brazil), Toxicity, physico-chemical parameters, bioindicator organisms.

\section{INTRODUÇÃO}

A água é um recurso de fundamental importância para os organismos vivos e imprescindível às diversas atividades humanas, sendo que as atividades antrópicas podem promover o comprometimento da qualidade dos recursos hídricos. O município de Criciúma está localizado no extremo sul catarinense e tem o Rio Sangão como um dos seus principais mananciais hídricos, cujos afluentes são os rios Maina, Criciúma, Cedro e Sanga do Terneiro, os quais pertencem à Região Hidrográfica 10 (RH10) (Galatto et al., 2011). O curso d'água do Rio Criciúma atravessa toda a região central da cidade e recebe diariamente resíduos provenientes da atividade carbonífera e de outros setores industriais, bem como comerciais, domésticos e hospitalares (Alexandre \& Krebs, 1995). Muito embora o Rio Criciúma esteja sujeito à contaminação por diversas classes de poluentes, ainda são poucos os estudos da qualidade de suas águas e dos possíveis efeitos tóxicos sobre a biota exposta. Neste contexto, a avaliação de parâmetros físicoquímicos de qualidade pode contribuir para este processo e, para tanto, se pode propor a determinação do $\mathrm{pH}$, oxigênio dissolvido (OD), Demanda Química de Oxigênio (DQO), demanda Bioquímica de Oxigênio (DBO) e Dureza.

Além da avaliação de parâmetros físico-químicos, é também relevante a utilização de ensaios ecotoxicológicos em organismos bioindicadores, como forma de se obter melhor avaliação da qualidade de mananciais hídricos contaminados 
(Tallini et al., 2012; Gomes et al., 2012). Neste contexto, tem sido proposto o uso de teste de toxicidade aguda em Daphnia spp pela avaliação do Fator de Toxicidade (FT). Este teste tem sido amplamente utilizado para este fim por apresentar características importantes, tais como grande potencial reprodutivo, fácil aquisição no mercado e manutenção em laboratório, boa reprodutividade e confiabillidade dos resultados (Arambasic et al., 1995; Silva, 2002; Sämy et al., 2010; Pimentel et al., 2011; Hamada et al., 2011). A utilização de plantas superiores também tem sido descrita como um ensaio sensível e rápido para a avaliação da contaminação atmosférica, terrestre e aquática (Calzoni et al., 2007). Em particular, tem-se sugerido o uso de Allium сера L. como organismo bioindicador para a avaliação ecotoxicológica de ambientes contaminados por várias classes de poluentes (Fiskesjö, 2006; Leme \& Marin-Morales, 2009). Para tanto, são avaliados diversos parâmetros fitotóxicos, tais como bioacumulação de contaminantes em diferentes tecidos (raízes, folhas e bulbos), inibição de crescimento de raízes e folhas, efeitos citogenéticos e mutagênicos, quando expostos a amostra teste. O uso deste vegetal em estudos ecotoxicológicos tem sido sugerido, uma vez que oferece benefícios como sensibilidade, reprodutibilidade, resposta em breve período de tempo, necessidade de pouco volume de amostra de contaminante, bem como baixo custo (Richa et al., 2005; Fatima \& Ahmad, 2005; Fatima \& Ahmad, 2006).

Testes de toxicidade aguda, sub-crônica e crônica avaliam parâmetros deletérios drásticos. Desta forma, o uso de biomarcadores de alterações bioquímicas, fisiológicas e morfológicas em organismos-teste vem ganhando espaço como mecanismo de avaliação de impacto ambiental (Streb et al., 2002). Dentre os biomarcadores, encontram-se os que indicam efeitos genotóxicos e, para tanto, podem ser empregados testes de fragmentação de DNA em células meristemáticas de Allium cepa L. e em tecidos de peixes Geophagus brasiliensis e em outras espécies (Bortolotto et al., 2009; Moreira et al., 2010; Hoshina \& Marin-Morales, 2010).

Portanto, o uso de testes ecotoxicológicos com diferentes organismos bioindicadores como microcrustáceos, peixes e vegetais aliado à determinação de parâmetros físico-químicos são ferramentas importantes para uma melhor avaliação da qualidade de mananciais hídricos contaminados por resíduos provenientes de atividade antrópica.

A partir destes pressupostos é que o presente trabalho propôs realizar estudos preliminares sobre o potencial tóxico das águas do Rio Criciúma, através da avaliação de parâmetros físico-químicos de qualidade e de ensaios com os organismos bioindicadores Daphnia magna, Allium cepa L. e Geophagus brasiliensis.

\section{MATERIAL E MÉTODO}

\section{Área de Estudo e Amostragem de Águas}

A área de estudo do presente trabalho está inserida na região sul do Estado de Santa Catarina, conhecida como
Bacia Carbonífera, pois encerra as maiores reservas de carvão metalúrgico economicamente explorável (SIECESC, 2013). Esta região está situada dentro das Bacias Hidrográficas do Rio Araranguá, Tubarão e Urussanga, ocupando uma área de $1050 \mathrm{~km}^{2}$. O município de Criciúma é um dos integrantes da Associação dos Municípios da Região Carbonífera (AMREC), situada no extremo sul do Estado de Santa Catarina (2840'40"S e $\left.49^{\circ} 22^{\prime} 12^{\prime \prime} \mathrm{W}\right)$. O município abrange uma superfície territorial de $235.628 \mathrm{~km}^{2}$, com uma altitude de $46 \mathrm{~m}$ e uma população estimada em 188.233 habitantes (IBGE, 2006). Sua área está limitada pelas cidades de Morro da Fumaça, Içara, Forquilhinha, Nova Veneza, Siderópolis e Cocal do Sul (AMREC, 1991). O tipo de clima é o subtropical úmido com verão quente (Cfa), pela classificação de Koeppen. A temperatura média anual é $19^{\circ} \mathrm{C}$ e a precipitação total média é de $1600 \mathrm{~mm}$, sem estação seca definida. As temperaturas médias mensais variam de $15^{\circ} \mathrm{C}$ no inverno a $24^{\circ} \mathrm{C}$ no verão, com possível ocorrência de geada. As chuvas são bem distribuídas ao longo do ano, com totais mensais variando de $80 \mathrm{~mm}$ em junho a $200 \mathrm{~mm}$ em fevereiro (CIRAM, 2012). Segundo o relatório do Departamento Nacional da Produção Mineral - DNPM (1987), a região foi categorizada como a $14^{\mathrm{a}}$ Área Crítica Nacional para o efeito de controle de poluição da qualidade ambiental, não só pelos impactos ambientais causados pela exploração do carvão mineral, como também por outros fatores, tais como a atividade agrícola, o desmatamento, a geração de efluentes industriais e domésticos. Estudos da qualidade de seus mananciais hídricos tem descrito a contaminação por metais (ex: ferro, alumínio, manganês, cobre, zinco etc), hidrocarbonetos policíclicos aromáticos (HPA), pesticidas, sulfatos, fosfatos, coliformes fecais e totais entre outros poluentes.

No presente trabalho, foram coletadas amostras de água superficiais (5L) a, aproximadamente, $30 \mathrm{~cm}$ de profundidade e distância de 1,0 $\mathrm{m}$ da margem, através da imersão de frasco de polietileno usado como recipiente coletor. Foi realizada uma coleta em 3 diferentes estações de amostragem, situadas no Rio Criciúma: a estação 1 (2839'58.00"S, 49²1'13.19"O, $136 \mathrm{~m}$ altitude) corresponde à proximidade da nascente, a estação 2 (2840'46.56”S, 49²2’31.22”O, 43m altitude) situa-se no intermédio da região central do cidade e a estação 3 (2841'45.24”S, 49²4'41.21'O, 31m altitude) localiza-se ao final da região central. As amostras foram e mantidas sob refrigeração $\left(4^{\circ} \mathrm{C}\right)$ até à execução dos ensaios. Todos os ensaios foram realizados nos laboratórios da Universidade do Extremo Sul Catarinense (UNESC), em Criciúma. A avaliação do $\mathrm{pH}$ foi realizada por potenciometria (pHmetro Analion). Para a determinação da DQO, utilizou-se o método analítico de refluxo aberto. Na análise da DBO utilizou-se o teste de DBO de cinco dias e o parâmetro OD foi obtido por oximetria (oxímetro Lutron DO 5510). A determinação da dureza foi realizada por titulometria do EDTA-Na (ABNT NBR 12621, 1995).

\section{Toxicidade aguda em microcrustáceos Daphnia magna}

Nos ensaios com Daphnia magna, organismos neonatos (2 a 26 h de vida; $\mathrm{n}=10$ ) foram expostos por 48 horas em béqueres contendo $20 \mathrm{~mL}$ de diluições seriadas $(100 ; 50$; 
33,$34 ; 25 ; 16,67 ; 12,5 ; 8,34 ; 6,25 ; 4,17 ; 3,12 ; 2,08 ; 1,56 ; 1,04$; 0,$78 ; 0,52 ; 0,39 \%$ ) das amostras de águas do Rio Criciúma, à temperatura de $20 \pm 2^{\circ} \mathrm{C}$, com fotoperíodo de 16 horas. Para o grupo controle negativo foi utilizada água de diluição. A toxicidade aguda foi avaliada através da determinação do Fator de Toxicidade (FT), o qual representa a menor diluição em que não se observa mortalidade superior a $10 \%$ dos organismos nas condições do ensaio (Lattuada et al., 2009).

\section{Fitotoxicidade em Allium cepa L.}

Para avaliar o efeito fitotóxico foi realizado teste de inibição do crescimento de raízes em Allium cepa L. de acordo com Bortolotto et al. (2009), com adaptações. Para tanto, amostras de $A$. cepa, obtidas a partir de fontes comerciais, tiveram suas raízes retiradas e os bulbos $(\mathrm{n}=6)$ colocados na parte superior de tubos de polietileno de fundo cônico, contendo $50 \mathrm{~mL}$ das amostras de água do Rio Criciúma, à temperatura ambiente e ao abrigo da luz. Para o controle negativo foi utilizada água mineral obtida comercialmente (marca comercial: Água Mineral da Guarda; Características físico-químicas e composição química descrito no rótulo: $\mathrm{pH}$ a $25^{\circ} \mathrm{C}=5,99$; temperatura na fonte $=34,6^{\circ} \mathrm{C}$; condutividade elétrica à $25^{\circ} \mathrm{C}=$ $105 \mu \mathrm{S} \mathrm{cm}^{-1}$; resíduos de evaporação a $180^{\circ} \mathrm{C}=90,23 \mathrm{mg} \mathrm{L}^{-1}$; radioatividade na fonte a $20^{\circ} \mathrm{C}$ e $760 \mathrm{mmHg}=53,36$ maches; bário $=0,012 \mathrm{mg} \mathrm{L}^{-1}$; bicarbonato estequiométrico $=29,80 \mathrm{mg}$ $\mathrm{L}^{-1}$; brometo $=0,04 \mathrm{mg} \mathrm{L}^{-1}$; cálcio $=4,624 \mathrm{mg} \mathrm{L}^{-1}$; cloreto $=$ $9,52 \mathrm{mg} \mathrm{L}^{-1}$; estrôncio $=0,013 \mathrm{mg} \mathrm{L}^{-1}$; fluoreto $=0,82 \mathrm{mg} \mathrm{L}^{-1}$; magnésio $=1,144 \mathrm{mg} \mathrm{L}^{-1}$; nitrato $=3,74 \mathrm{mg} \mathrm{L}^{-1}$; potássio $=$ 4,08 $\mathrm{mg} \mathrm{L}^{-1}$; lítio $=0,005 \mathrm{mg} \mathrm{L}^{-1}$; silício $=17,673 \mathrm{mg} \mathrm{L}^{-1}$; sódio $=11,081 \mathrm{mg} \mathrm{L}^{-1}$; sulfato $=2,48 \mathrm{mg} \mathrm{L}^{-1}$ ). As amostras foram reabastecidas diariamente, de forma a manter os bulbos sempre em contato com as mesmas. Após sete dias de exposição, foi medido o comprimento da maior raiz de cada bulbo.

\section{Teste de genotoxicidade em Allium cepa L. e em Geophagus brasiliensis}

O potencial genotóxico foi avaliado, utilizando teste de fragmentação do DNA (teste Cometa) proposto por Singh et al. (1988), com modificações. Para tanto, indivíduos de Allium cepa $\mathrm{L}$. $(\mathrm{n}=6)$ foram expostos às mesmas condições do ensaio de fitotoxicidade. Ao final da exposição, células meristemáticas foram retiradas da região apical das raízes e homogeneizadas em solução de extração de núcleo. O homogenato foi diluído em agarose de baixo ponto de fusão $(0,75 \%)$ e espalhado sobre lâminas de microscópio précobertas com agarose 1,5\% em duplicata. Após ficarem mergulhadas em solução de lise a $4^{\circ} \mathrm{C}$ por 2 horas, as lâminas foram submetidas à eletroforese alcalina por 30 minutos a $300 \mathrm{~mA}$ e $25 \mathrm{~V}$. Após a eletroforese, as lâminas foram lavadas em tampão de neutralização, enxaguadas em água deionizada e submetidas à solução de fixação por 10 minutos. As lâminas foram coradas e analisadas em microscópio óptico com aumento de 100X, sendo os resultados expressos como Índice de Dano ao DNA, com escore de 0 a 400, empregando-se unidade arbitrária.
Nos ensaios com peixes, indivíduos jovens de $G$. brasiliensis $(10 \pm 2 \mathrm{~cm}$ de comprimento; $35 \pm 5 \mathrm{~g}$ de peso corpóreo) foram mantidos em aquários de vidro, contendo água mineral (1 peixe/5L de água), em constante aeração, com fotoperíodo claro/escuro de 12 horas, à temperatura de $24 \pm 2^{\circ} \mathrm{C}$, alimentados diariamente ad libidum por 7 dias para aclimatação. Ao final deste período, os peixes foram divididos em grupos de seis indivíduos e expostos por 2 horas às águas coletadas nas 3 diferentes estações do Rio Criciúma. Para o grupo controle negativo, foi utilizada água mineral comercial, cuja marca comercial, características físico-químicas e composição química já foram descritas anteriormente. Ao final da exposição, foi coletado sangue periférico por punção cardíaca usando seringa contendo heparina. Os animais foram mortos, sendo o fígado imediatamente retirado. $\mathrm{O}$ sangue e o fígado foram homogeneizados em tampão PBS ("phospate-bufferedsaline") e colocados em $95 \mu \mathrm{L}$ de agarose de baixo ponto de fusão $(0,75 \%)$ e espalhado sobre lâminas de microscópio cobertas com agarose $1,5 \%$, em duplicata. As lâminas foram submetidas ao teste cometa, já descrito anteriormente, sendo também avaliado o Índice de Dano ao DNA.

\section{ANÁLISE ESTATÍSTICA}

Os resultados dos testes de fitotoxicidade e genotoxicidade foram submetidos à análise de Variância (ANOVA), complementada pelo teste de Bonferroni. As análises foram conduzidas usando "software" GraphPad Prism 5.0 (GraphPad Inc. San Diego, California, U.S.A.), assumindo nível de significância de $\mathrm{p}<0,05$. Todos os resultados foram expressos em Média \pm Desvio Padrão.

\section{RESULTADOS E DISCUSSÃO}

\section{Parâmetros físico-químicos das águas do Rio Criciúma}

A determinação de parâmetros físico-químicos tais como pH, DBO, DQO, OD e Dureza é uma importante ferramenta de avaliação da qualidade de ambientes hídricos. Os resultados obtidos nos parâmetros físico-químicos das águas coletadas nas estações do Rio Criciúma estão apresentados na Tabela 1. Comparando-se os resultados entre as estações de coleta, é possível constatar que os valores de $\mathrm{pH}$ se mostraram próximos entre si e ligeiramente ácidos. Este parâmetro pode ser considerado como uma das variáveis ambientais mais

Tabela 1 - Parâmetros físico-químicos das águas coletadas nas estações do Rio Criciúma.

\begin{tabular}{|c|c|c|c|}
\hline \multirow[t]{2}{*}{ Parâmetros } & \multicolumn{3}{|c|}{ Estações } \\
\hline & 1 & 2 & 3 \\
\hline $\mathrm{pH}$ & 6,1 & 6,5 & 6,1 \\
\hline DBO 5 dias $\left(\mathrm{mg} \mathrm{L}^{-1}\right)$ & 2 & 44 & 6 \\
\hline $\mathrm{DQO}\left(\mathrm{mg} \mathrm{L}^{-1}\right)$ & 8,6 & 88 & 38 \\
\hline $\mathrm{OD}\left(\mathrm{mg} \mathrm{L}^{-1}\right)$ & 6,1 & 4,2 & 4,5 \\
\hline Dureza $\left(\mathrm{mg} \mathrm{L}^{-1} \mathrm{CaCO}_{3}\right)$ & 178 & 70 & 96 \\
\hline
\end{tabular}


importantes em ecossistemas aquáticos, pois ele interfere em processos bioquímicos, no balanço de $\mathrm{CO}_{2}$, na natureza química da água e na solubilidade de sais (Rodrigues et al., 2000).

Em nossos estudos foi possível observar que os valores de $\mathrm{DBO}$ e DQO das águas coletadas na estação $2(\mathrm{DBO}=44 \mathrm{mg}$ $\mathrm{L}^{-1}$ e DQO $\left.=88 \mathrm{mg} \mathrm{L}^{-1}\right)$ e estação $3\left(\mathrm{DBO}=6 \mathrm{mg} \mathrm{L}^{-1}\right.$ e $\mathrm{DQO}=$ $38 \mathrm{mg} \mathrm{L}^{-1}$ ) estiveram acima dos observados na estação 1 (DBO $\left.=2 \mathrm{mg} \mathrm{L}^{-1} \mathrm{eDQO}=8,6 \mathrm{mg} \mathrm{L}^{-1}\right)$. Constatou-se valores menores de OD na estação $2\left(4,2 \mathrm{mg} \mathrm{L}^{-1}\right)$ e estação $3\left(4,5 \mathrm{mg} \mathrm{L}^{-1}\right)$, quando comparados à estação $1\left(6,1 \mathrm{mg} \mathrm{L}^{-1}\right)$. Os valores maiores de DBO e DQO e menores de OD observados nas estações 2 e 3 poderiam estar associados às altas concentrações de substâncias orgânicas provenientes da descarga de esgotos domésticos e resíduos industriais lançados diariamente no leito do rio (Alexandre \& Krebs, 1995). Estas substâncias podem servir como fonte de alimento para microrganismos decompositores e aumento de sua proliferação, com consequente elevação do consumo de oxigênio e diminuição dos valores de oxigênio dissolvido (Mota, 1995; Sperling, 2002). O oxigênio é um elemento de essencial importância para organismos aeróbicos e o aumento da taxa de seu consumo pode provocar hipóxia, causando efeitos nocivos à biota. Em geral, valores de OD inferiores a $2 \mathrm{mg} \mathrm{L}^{-1}$ indicam ambiente aquático em hipóxia (Lindenschmidta et al., 2009). Entretanto, esta condição não foi observada em nossos resultados, uma vez que os valores de OD nas águas do rio coletadas nas diferentes estações se mostraram superiores à referida concentração.

Em relação ao parâmetro da Dureza, observa-se que as águas da estação 1 apresentaram valores maiores, quando comparado aos demais pontos de coleta. Este perfil poderia estar associado a uma maior concentração de íons carbonatos e bicarbonatos presentes no ponto inicial do corpo hídrico. As águas da estação 1 apresentaram valores dentro do intervalo de águas enquadradas como duras (150-300 $\left.\mathrm{mg} \mathrm{L}^{-1}\right) \mathrm{e}$ as das estações 2 e 3 como moderadamente duras $\left(75-150 \mathrm{mg} \mathrm{L}^{-1}\right)$, o que poderia ser caracterizadas como compatíveis para os sistemas biológicos (Mendes et al., 2008).

Trabalhos na literatura também tem descrito o comprometimento da qualidade das águas do Rio Criciúma em termos de parâmetros físico-químicos. Alexandre \& Krebs (1996) observaram baixos valores de $\mathrm{pH}(4,56$ a 6,25) e de OD (0,25 a 1,32 $\left.\mathrm{mg} \mathrm{L}^{-1}\right)$, bem como elevados valores de DBO $\left(69,01\right.$ a $\left.481,92 \mathrm{mg} \mathrm{L}^{-1}\right)$ e de DQO $(287,38$ a $1.010,97 \mathrm{mg}$ $\left.\mathrm{L}^{-1}\right)$ em amostras de águas coletadas em diferentes pontos do Rio Criciúma, sendo sugerido que os mesmos poderiam ser decorrentes da contaminação das águas por resíduos da mineração de carvão, esgotos domésticos, comerciais e industriais. Semelhante perfil também foi descrito por Schnack (2007), onde foi constatado baixo valor de OD $\left(3,25 \mathrm{mg} \mathrm{L}^{-1}\right) \mathrm{e}$ de $\mathrm{pH}(5,32)$ e valor de Dureza de $119,17 \mathrm{mg} \mathrm{L}^{-1}$ em amostras de águas do Rio Criciúma em virtude da possível presença de contaminantes ambientais em solução. Galatto et al. (2011) constataram elevada concentração de ferro e manganês em amostras de águas coletadas na nascente do Rio Criciúma.

Portanto, os resultados dos parâmetros físico-químicos obtidos em nossos estudos permitem sugerir que águas do Rio Criciúma coletadas na região central estariam com a sua qualidade comprometida, sugerindo o seu potencial tóxico para a biota exposta.

\section{Toxicidade aguda em Daphnia magna}

Ensaios de toxicidade aguda têm sido utilizados como ferramenta para a avaliação do potencial efeito tóxico de mananciais hídricos em organismos bioindicadores, incluindose os microcrustáceos (Mendes et al., 2011).

Os resultados obtidos no teste de toxicidade aguda em microcrustáceos Daphnia magna expostos às águas coletadas nas estações do Rio Criciúma estão descritos na Tabela 2. Pode-se constatar que houve toxicidade aguda somente nos organismos expostos às águas coletadas na estação 2 , sendo que nas demais não foi constatada mortalidade nas diferentes diluições utilizadas nas amostras.

Schnack (2007) também observou toxicidade aguda em Daphnia magna $(\mathrm{FT}=5,9)$ quando exposta às águas do Rio Criciúma, sendo sugerido que o efeito deletério estaria associado à contaminação por diferentes poluentes. Outros trabalhos da literatura também tem descrito toxicidade aguda nestes microcrustáceos, quando expostos à água de rios atingidos por vários tipos de contaminantes, incluindose efluentes industriais e domésticos, resíduos hospitalares contendo metais, compostos orgânicos halogenados e coliformes fecais (Emmanuela et al., 2005; Geremias et al., 2008; Lattuada et al., 2009; Xianliang et al., 2010).

Tem-se proposto que em ambientes aquáticos atingidos por contaminantes pode haver distúrbios respiratórios, osmorregulatórios, processos mutagênicos e cancerígenos e até a morte da biota exposta (Ridge \& Seif, 1998). Desta forma, o efeito deletério nos microcrustáceos observados em nossos estudos poderia estar associado à presença de contaminantes lançados no corpo hídrico.

\section{Fitotoxicidade em Allium cepa $L$.}

O emprego de testes de fitotoxicidade utilizando Allium cepa L. como organismo bioindicador tem sido recomendado para a avaliação da qualidade de ambientes aquáticos (Mendes et al., 2011).

Os resultados observados no teste de inibição do crescimento de raízes em Allium cepa $\mathrm{L}$. expostos às águas do Rio Criciúma nas diferentes estações de coleta e à água mineral (controle negativo) estão apresentados na Figura 1. Foi possível constatar que as águas coletadas nas estações 2 e 3 provocaram significativa inibição do crescimento das raízes, quando comparado controle negativo. Outros trabalhos da literatura também tem relatado inibição de crescimento de raízes de Allium cepa L. exposta a mananciais hídricos e a efluentes

Tabela 2 - Toxicidade aguda em Daphnia magna expostos às águas coletadas nas diferentes estações do Rio Criciúma.

\begin{tabular}{lc}
\hline Estações & Fator de Toxicidade (FT) \\
\hline 1 & 1 \\
2 & 3 \\
3 & 1 \\
\hline
\end{tabular}




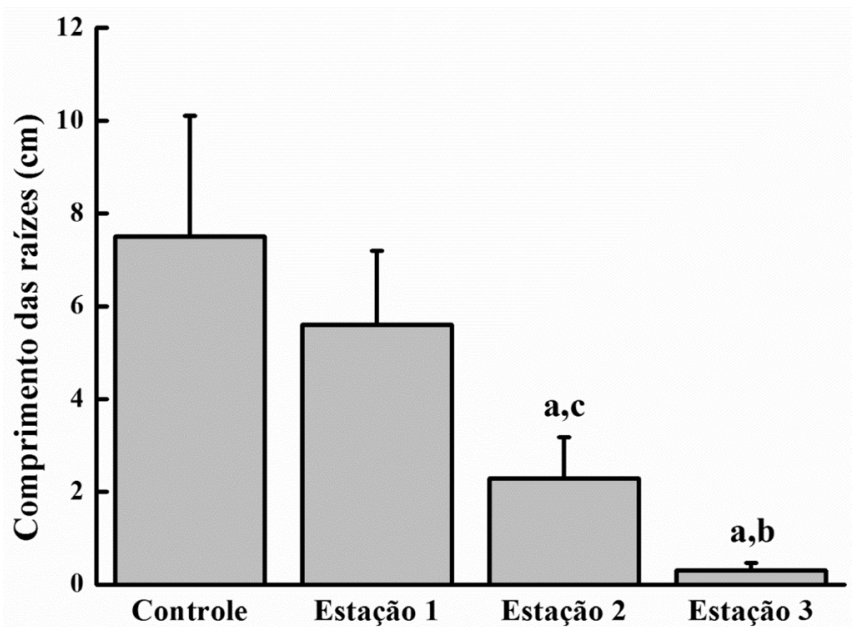

Figura 1. Inibição do crescimento das raízes em Allium cepa L. expostas às águas coletadas nas diferentes estações do Rio Criciúma e à água mineral como controle negativo. (a) Representa diferença significativa $(p<0,001)$ em relação ao controle negativo; (b) Representa diferença significativa $(\mathrm{p}<0,001)$ em relação à estação $1 ;$ (c) Representa diferença significa $(\mathrm{p}<0,01)$ em relação à estação 1 . Análise de Variância (ANOVA), complementada pelo teste de Bonferroni.

oriundos de diversas atividades antrópicas (Srivastava et al., 2005; Radića et al., 2010; Geremias et al., 2012).

A inibição do crescimento de raízes poderia estar relacionada à presença de contaminantes no meio aquático, tais como metais e compostos orgânicos, os quais poderiam comprometer a produção de células meristemáticas (Dovgaliuk et al., 2001; Patrícia et al., 2003; Ezaki et al., 2004; Ledislav et al., 2006; Glińska et al., 2007).

Conforme também constatado com os microcrustáceos, não foi observado o efeito fitotóxico no grupo exposto às águas coletadas na estação 1 , provavelmente em virtude de sua melhor qualidade, quando comparado às demais estações de coleta. Entretanto, observou-se diferença de resultados entre Daphnia magna e Allium cepa L. expostos às águas coletadas na estação 3 , o que poderia estar associada à diferença em seus mecanismos de proteção e/ou detoxificação frente à exposição a xenobióticos específicos, conforme já discutido anteriormente.

Portanto, nossos resultados permite sugerir que as águas da região central do Rio Criciúma foram capazes de promover efeitos fitotóxicos, sugerindo o comprometimento de sua qualidade.

\section{Teste de genotoxicidade em Allium cepa L. e em Geophagus brasiliensis.}

A utilização de biomarcadores de genotoxicidade, especificamente, teste de fragmentação do DNA é de grande relevância para avaliação de qualidade de ambientes aquáticos, uma vez que são capazes de detectar alterações em nível biológico antes mesmo do surgimento de efeitos letais (Geremias et al., 2012).

As Figuras 2 e 3 apresentam, respectivamente, os resultados dos testes de genotoxicidade em Allium cepa L. e em peixes

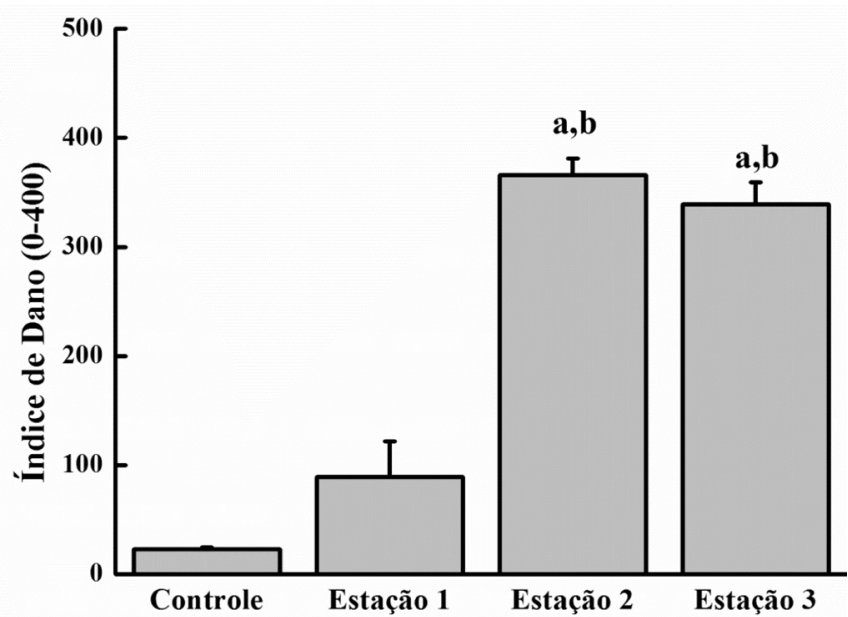

Figura 2. Índice de Dano ao DNA em Allium cepa L. expostas às águas coletadas nas diferentes estações do Rio Criciúma e à água mineral como controle negativo. (a) Representa diferença significativa $(p<0,001)$ em relação ao controle negativo; (b) Representa diferença significativa $(\mathrm{p}<0,001)$ em relação à estação 1 . Análise de Variância (ANOVA), complementada pelo teste de Bonferroni.
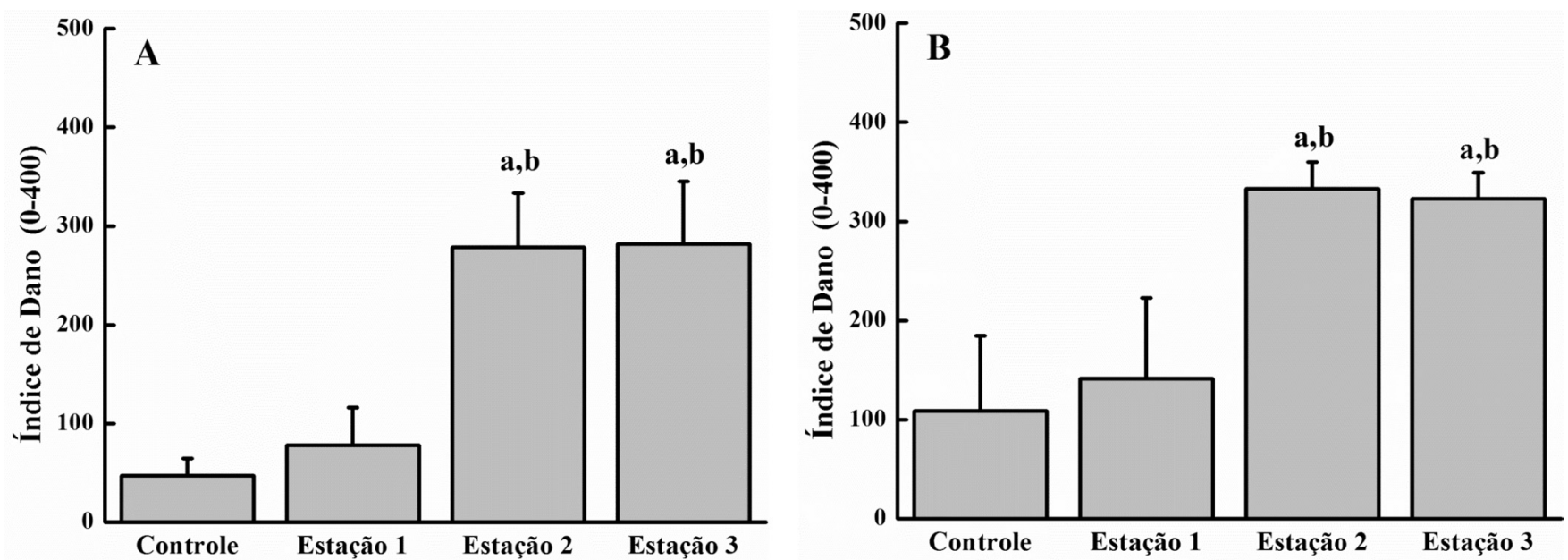

Figura 3. Índice de Dano ao DNA em células sanguíneas (A) e em fígado (B) de Geophagus brasilienses expostos às águas coletadas nas diferentes estações do Rio Criciúma e à água mineral como controle negativo. (a) Representa diferença significativa $(\mathrm{p}<0,001)$ em relação ao controle negativo; (b) Representa diferença significativa $(p<0,001)$ em relação à estação 1. Análise de Variância (ANOVA), complementada pelo teste de Bonferroni. 
Geophagus brasiliensis expostos às águas do Rio Criciúma coletadas nas diferentes estações, bem como à água mineral como controle negativo. Pode-se constatar significativo índice de dano ao DNA em ambos os organismos bioindicadores expostos às águas coletadas nas estações 2 e 3, quando comparados à estação $1 \mathrm{e}$ ao controle negativo.

Em trabalho descrito por Teixeira et al. (2004) também foi constatado significativo índice de dano ao DNA determinado pelo teste cometa em Allium cepa L. expostas às águas coletadas em rio da região sul catarinense (ID $=150,3 \pm 11,5$ ), quando comparado ao controle negativo (ID $=47,1 \pm 4,5$ ), tendo sido sugerido que o efeito genotóxico seria decorrente da contaminação das águas por resíduos da mineração de carvão. Benassi et al. (2006) avaliaram genotoxicidade em sangue e figado de tilápia (Oreochromis niloticus) pelo teste cometa, ao serem expostos por 7, 15 e 30 dias a efluentes gerados na mineração de carvão coletados no município de Siderópolis, região sul de Santa Catarina. Foi observado aumento no índice de Dano ao DNA em células hepáticas ( $50 \%$ em 7 e 15 dias) e em sangue ( $79 \%, 77 \%$ e $48 \%$ aos 7,15 e 30 dias, respectivamente).

O efeito genotóxico observado em nossos estudos poderia estar associado à capacidade dos contaminantes presentes nas águas em reagir diretamente com biomoléculas ou de forma indireta, promovendo alteração estrutural e funcional do DNA, com conseqüente processo de mutagênese, carcinogênese, teratogênese, aberrações cromossômicas, distúrbios do ciclo celular e da divisão celular, apoptose e fragmentação do DNA (Athanasios et al., 2000; Gerber et al., 2002; Greenwell et al., 2002; Lingard et al., 2005; Gilli et al., 2007).

Portanto, os resultados obtidos em todos os ensaios realizados no presente estudo permitem sugerir que as águas do Rio Criciúma coletadas na região central da cidade (estações 2 e 3 ) apresentaram valores aumentados DBO e DQO e menores de $\mathrm{OD}$, quando comparados às águas próximas a nascente (estação 1). Semelhante perfil também foi observado nos ensaios com os organismos bioindicadores, nos quais foram constatados efeitos tóxicos e genotóxicos frente à exposição às águas coletadas na região central. Estes resultados permitem sugerir uma melhor qualidade das águas no ponto inicial do rio, vindo a ser comprometida ao longo de sua passagem pela região central da cidade, provavelmente em virtude da descarga de contaminantes potencialmente tóxicos oriundos das atividades antrópicas, notadamente, de resíduos industriais, comerciais, domésticos e hospitalares que são diariamente lançados em suas águas.

\section{CONCLUSÃO}

A partir dos resultados obtidos, é possível concluir que as águas do Rio Criciúma coletadas nas estações da região central da cidade apresentaram valores de parâmetros físico-químicos capazes de comprometer os sistemas biológicos da biota exposta, quando comparados às amostras da região próxima à nascente do rio. Da mesma forma, também foram evidenciados efeitos tóxicos agudos em microcrustáceos Daphnia magna e fitotóxico em Allium cepa L., bem como genotoxicidade em Allium cepa L. e em peixes Geophagus brasiliensis quando expostos às águas coletadas nas estações da região central, estando estes efeitos ausentes na exposição às águas do ponto inicial do rio. Os resultados permitem demonstrar o comprometimento da qualidade das águas partir de sua passagem pela região central da cidade, o que poderia estar associado ao lançamento de contaminantes provenientes de diferentes atividades antrópicas. Estes estudos são considerados preliminares e, para que se tenha um melhor diagnóstico da qualidade das águas do Rio Criciúma, são necessários trabalhos complementares, utilizando coletas periódicas e avaliando diferentes ensaios ecotoxicológicos e outros parâmetros físico-químicos de qualidade, além da análise de possíveis contaminantes presentes no corpo hídrico.

\section{AGRADECIMENTOS}

Os autores agradecem à Universidade do Extremo Sul Catarinense e à Universidade Federal de Santa Catarina pelo suporte técnico e financeiro.

\section{REFERÊNCIAS}

ABNT (Associação Brasileira de Normas Técnicas), 1995, NBR 12621. Água. Determinação da dureza total-Método titulométrico do EDTA-Na,ABNT, Rio de Janeiro, 4 p.

ALEXANDRE, N.Z. \& KREBS, A.S.J., 1996. Discussão da aplicação do método do IQA na avaliação da qualidade das águas da região carbonífera de Santa Catarina. Rev. Tecnol. Ambiente, 2:31-52.

ALEXANDRE, N.Z. \& KREBS, A.S.J., 1995, Qualidade das águas superficiais do município de Criciúma, SC. Porto Alegre: CPRM, $73 p$.

ARAMBASIC, M.B., BJELIC, S. \& SUBAKOV, G., 1995, Acute toxicity of heavy metals (copper, lead, zinc), phenol and sodium on Allium cepa L., Lepidium sativum L. and Daphnia magna St.: Comparative investigations and the practical applications. Water Res., 29:497-503. http://dx.doi.org/10.1016/j.etap.2009.05.007.

ATHANASIOS, V., SALIKA, A. \& THEODOROPOULOU, A., 2000, Generation of hydroxyl radicals by urban suspended particulate air matter. The role of iron íons. Atmos Environ., 34:2379-2386.

BORTOLOTTO, T., BERTOLDO, J. B., SILVEIRA, F. Z., DEFAVERI, T. M., SILVANO, J. \& PICH, C. T., 2009. Evaluation of the toxic and genotoxic potential of landfill leachates using bioassays. Environ Toxicol Pharmacol., 28: 288293. http://dx.doi.org/doi: 10.1016/j.etap.2009.05.007.

BENASSI, J.C., LAUS, R., GEREMIAS, R., LIMA, P.L., MENEZES, C.T., LARANJEIRA, M.C., WILHELM-FILHO, D., FÁVERE, V.T. \& PEDROSA, R.C., 2006, Evaluation of remediation of coal mining wastewater by chitosan microspheres using biomarkers. Arch Environ. Contam. Toxicol., 51:633-40.

CALZONI, G.L., ANTOGNONI, F., PARI, E., FONTI, P., GNES, A. \& SPERANZA, A., 2007, Active biomonitoring of heavy metal pollution using Rosa rugosa plants. Environ. Pollut., 149:239-245. http://dx.doi.org/doi:10.1016/j.envpol.2006.12.023.

CIRAM (Centro de Informações de Recursos Ambientais e de Hidrometereologia de Santa Catarina). Disponível em: http://www. ciram.com.br/siscrici/index.jsp?url=pagina/jsp/ projeto.jsp. Acesso em: 25 maio 2012

DERISIO, J.C. Introdução ao controle de poluição ambiental. São 
Paulo: Cetesb, 1992, 210p.

DNPM (Departamento Nacional da Produção Mineral), 1987, Perfil analítico do carvão. Boletim n ${ }^{\circ}$ 6. Ministério das Minas e Energia. Porto Alegre.

DOVGALIUK, A.L., KALINIAK, T.B. \& BLIUM, I.A.B., 2001, Cytogenetic effects of toxic metal salts on apical meristem cells os Allium cepa L. seed roods. Tsitol. Genet., 35:3-10.

EMMANUELA, Y.E., PERRODIN, G., KECK, J.M. \& BLANCHARD, P. V., 2005, Ecotoxicological risk assessment of hospital wastewater: a proposed framework for raw effluents discharging into urban sewer network. J Hazard Mater., 117:111. http://dx.doi.org/doi:10.1016/j.jhazmat.2004.08.032

EZAKI, B., SUZUKI, M., MOTODA, H., KAWAMURA, M., NAKASHIMA, S. \& MATSUMOTO, H., 2004, Mechanism of gene expression of Arabidopsis gluthatioe-S-transferase, At GST1 and AtGST11 in response to aluminum stress. Plant Physiol., 134:1672-1682.

FATIMA, R. A. \& AHMAD, M., 2005, Certain antioxidant enzymes of Allium cepa as biomarkers for the detection of toxic heavy metals in wastewater. Sci. Total Environ., 346:256-273. http:// dx.doi.org/doi:10.1016/j.scitotenv.2004.12.004.

FATIMA, R.A. \& AHMAD, M., 2006, Allium cepa EROD as a potential biomarker for the presence of certain pesticids in walter. Chemosphere, 62:527-537. http://dx.doi.org/ doi:10.1016/j.chemosphere.2005.06.032.

FISKESJÖ, G., 2006, The Allium test in wastewater monitoring. Environ. Toxicol. Walter Qual., 8:291-298. http://dx.doi.org/ doi:10.1002/tox.2530080306.

GALATTO, S.L., ALEXANDRE, N.Z., PEREIRA, J.L., PATRÍCIO, T.B., VASSILIOU, M., FERNANDES, A.N., FRASSETTO, J. \& VALVASSORI, M.L., 2011, Diagnóstico ambiental de nascentes no município de Criciúma, Santa Catarina. Revista de Ciências Ambientais, 5:39 -56.

GERBER, G.B., LÉONARD, A. \& HANTSON, P., 2002, Carcinogenicity, mutagenicity and teratogenicity of manganese compounds. Crit. Rev. Oncol. Hematol., 42:25-34.

GEREMIAS, R., BORTOLOTTO, T., WILHELM-FILHO, D., PEDROSA, R.C. \& FÁVERE, V.T., 2012, Efficacy assessment of acid mine drainage treatment with coal mining waste using Allium cepa L. as a bioindicator. Ecotoxicol. Environ. Saf., 79:116-121. http://dx.doi.org/doi: 10.1016/j. ecoenv.2011.12.010.

GEREMIAS, R., LAUS, R., MACAN, J.M., PEDROSA, R.C., LARANJEIRA, M.C.M., SILVANO, J. \& FAVERE, V.T., 2008, Use of coal mining waste for the removal of acidity and metal ions $\mathrm{Al}$ (III), Fe (III) and $\mathrm{Mn}$ (II) in acid mine drainage. Environ Technol., 29:863-886. http://dx.doi.org/ doi:10.1080/09593330802015409.

GILli, G., TRAVERSI, D., ROVERE, R., PIGNATA, C. \& SCHILIRÒ, T., 2007, Chemical characteristics and mutagenic activity of PM10 in Torino, a Northern Italian City. Sci Total Environ., 385:97-107. http://dx.doi.org/doi:10.1016/j. scitotenv.2007.07.006

GLIŃSKA, S., BARTCZAK, M., OLEKSIAK, S., WOLSKA, A., GABARA, B., POSMYK, M. \& JANAS, K., 2007, Effects of anthocyanin-rich extract from red cabbage leaves on meristematic cells of Allium cepa L. roots treated with heavy metals. Ecotoxicol. Environ. Saf., 68:343-50. http://dx.doi.org/ doi:10.1016/j.ecoenv.2007.02.004.

GOMES, L.S., SILVA, F.A., BARBOSA, S. \& KUMMROW, F., 2012, Ecotoxicity of Sludges Generated by Textile Industries: a Review. J. Braz. Soc. Ecotoxicol., 7:89-96. http://dx.doi.org/ doi:10.5132/jbse.2012.01.013.

GREENWELL, L.L., MORENO, T., JONES, T.P. \& RICHARDS,
R.J., 2002, Particle-induced oxidative damage is ameliorated by pulmonary antioxidants. Free Radic Biol Med., 32: 898-905.

HAMADA N., MESQUITA, L. C. A., PEREIRA, I. W., NAKANO, E., BORRELY, S. I. \& TALLARICO, L. F., 2011, Avaliação Ecotoxicológica da Estação de Tratamento de Esgotos Suzano (São Paulo) Utilizando Daphnia similis e Vibrio fischeri. J. Braz. Soc. Ecotoxicol., 6:31-35. http://dx.doi.org/doi:10.5132/ jbse.2011.01.005

HOSHINA, M. M. \& MARIN-MORALES, M. A., 2010, Evaluation of the Genotoxicity of PetroleumRefinery Effluents Using the Comet Assay in Oreochromis niloticus (Nile tilapia). J. Braz. Soc. Ecotoxicol., 5:75-79. http://dx.doi.org/doi:10.5132/ jbse.2010.01.012

IBGE (Instituto Brasileiro de Geografia e Estatística), 2006, Indicadores de desenvolvimento sustentável - Brasil 2004. Rio de Janeiro, p.364.

LATTUADA, R.M., MENEZES, C.T., PAVEI, P.T., PERALBA, M.C. \& SANTOS, J.H., 2009, Determination of metals by total reflection X-ray fluorescence and evaluation of toxicity of a river impacted by coal mining in the south of Brazil. J Hazard Mater., 163:531-537. http://dx.doi.org/doi:10.1016/j. jhazmat.2008.07.003

LEDISLAV, T., JANA, H., IGOR, M., MARTA, S. \& BEATA, S., 2006, Aluminum-induced drought and oxidative stress in barley roots. J. Plant Physiol., 163:781-784. http://dx.doi.org/ doi:10.1016/j.jplph.2005.08.012

LEME, D.M. \& MARIN-MORALES, M.A., 2009, Allium cepa test in environmental monitoring: A review on its application. Mutat. Res., 682:71-81. http://dx.doi.org/doi:10.1016/j. mrrev.2009.06.002.

LINDENSCHMIDTA, K. E., PECHA, I. \& BABOROWSKIB, M., 2009, Environmental risk of dissolved oxygen depletion of diverted flood waters in river polder systems - A quasi-2D flood modelling approach. Sci. Total Environ., 407:1598 1612. http://dx.doi.org/doi:10.1016/j.scitotenv.2008.11.024.

LINGARD, J.J.N., TOMLIN, A.S., CLARKE, A.G., HEALE, K., HAY, A.W.M., WILD, C.P. \& ROUTLEDGE, M., 2005, A study of trace metal concentration of urban airborne particulate matter and its role in free radical activity as measured by plasmid strand break assay. Atmos Environ., 39: 2377-2384. http://dx.doi.org/ doi:10.1016/j.atmosenv.2004.05.063

MENDES, J.C., CHAVES, L.H.G., \& CHAVES, I.B., 2008 , Qualidade de água para consumo humano em comunidades rurais do município de Congo, PB1. Rev. Ciên. Agron., 39, 333-342.

MENDES, B.G., BUDZIAK, D., STOLBERG, J., PEIXER, Z.I., DALMARCO, J.B., SIMIONATTO, E.L., PEDROSA, R.C., FELIPE, K.B., OGAWA, J., PEGORARO, C., SCHEFFER, L., BESEN, M.R., OLIVEIRA, L.J.G.G \& GEREMIAS, R., 2011, Estudo da qualidade das águas do Rio Marombas(SC/Brasil), utilizando parâmetros físico-químicos e bioensaios. Revista de Ciências Ambientais, 5:43-58.

MOREIRA, T.N., NUNES, E.A., LEAL, M.E., SCHULZ, U. H. \& LEMOS, C. T., 2010, Influência dos Métodos de Captura de Peixes na Avaliação Genotóxica Utilizando Diferentes Tecidos de Astyanax fasciatus (Osteichthyes, Characidae). J. Braz. Soc. Ecotoxicol., 5:1-7. http://dx.doi.org/doi:10.5132/ jbse.2010.01.001

MOTA, S., 1995, Preservação e conservação de recursos hídricos. 2. ed., Rio de Janeiro: ABES, 187 p.

PATRICIA, R.S.B., MARCELO, M. \& RENATO A.J., 2003, Aluminum induced oxidative stress in maize. Phytochemistry, 62:181-189.

PIMENTEL, M. F., SILVA JÚNIOR, F. C. G., SANTAELlA, S. T. \& LOTUFO, L. V. C., 2011, O Uso de Artemia sp. 
como organismo-teste para avaliação da toxicidade das águas residuárias do beneficiamento da castanha de caju antes e após tratamento em reator biológico experimental, J. Braz. Soc. Ecotoxicol., 6:15-22. http://dx.doi.org/doi: 10.5132/ jbse.2011.01.003.

RADIĆA, S., STIPANIČEV, D., VUJČIĆ, V., RAJČIĆ, M.M., ŠIRAC,S. \& PEVALEK-KOZLINA, B., 2010, The evaluation of surface and wastewater genotoxicity using the Allium cepa test. Sci Total Environ., 408:1228-1233. http://dx.doi.org/doi: 10.1016/j.scitotenv.2009.11.055.

RICHA, S., DINESH, K. \& GUPTA, S.K., 2005, Bioremediation of municipal sludge by vermitechnology and toxicity assessment by Allium cepa. Bioresour. Technol., 96:1867-1871. http://dx.doi. org/doi:10.1016/j.biortech.2005.01.029.

RIDGE, T. \& SEIF, J.M., 1998, Coal mine drainage predicition an pollution prevention in Pennsylvania. Pennsylvania: Pennsylvania Department of Environmental Protection, 398 p.

RODRIGUES, M. T, R., MACHADO, N.A.F., LEONARDI, S.M., PELLINI, G.F., ABEL, L., PEDROZO, C., BRUSCHI, W., OLIVEIRA, M.F. \& ATZ, V.L., 2000, Parâmetros físicos e químicos das águas superficiais e avaliação da atividade bacteriana em ambientes lóticos receptores da drenagem de mineração de carvão. In: Carvão e Meio Ambiente. Porto Alegre: Ed. Universidade UFRGS, $1006 \mathrm{p}$.

SÄMY, C. H., TORRENS, B.M.O. \& MEDEIROS, S. H.W., 2010, Estudo do impacto ambiental na bacia do Rio do Braço através de análises ecotoxicológicas. Revista de Ciências Ambientais, 4:45-55.

SCHNACK, C.E., Utilização de teste ecotoxicológico para a avaliação da confluência das águas dos Rios Criciúma e Sangão, Criciúma-SC. 2007, 35f. Trabalho de Conclusão de Curso (Graduação em Ciências Biológicas) - Universidade do Extremo Sul Catarinense.

SIECESC (Sindicato das Indústrias da Extração de Carvão do Estado de Santa Catarina), Carvão mineral: Dados estatísticos ano 2002. Disponível em: <http://www.siecesc.com.br/estatisticas/>.
Acesso em: 26 fev 2013.

SILVA, A. C. Tratamento do percolado de aterro sanitário e avaliação da toxicidade. 2002, 126f. Dissertação (Mestrado em Engenharia Civil) - Universidade Federal do Rio de Janeiro.

SINGH, N.P., MCCOY, M.T., TICE, R.R., SCHNEIDER, E.L., 1988, A simple technique for quantitation of levels of DNA damage in individual cells. Exp. Cell Res., 175:184-191.

SPERLING, M. V. Introdução à qualidade das águas e ao tratamento de esgotos, 2002, 2.ed. Belo Horizonte: DESA, 243 p.

SRIVASTAVA, R., KUMAR, D. \& GUPTA, S.K., 2002, Bioremediation of municipal sludge by vermitechnology and toxicity assessment by Allium cepa. Bioresour. Technol., 96:186771. http://dx.doi.org/doi:10.1016/j.biortech.2005.01.029.

STREB, C., RICHTER, P., NTEFIDOU, M., LEBERT, M. \& HADER, D.P., 2002, ECOTOX - Biomonitoring based on real time movement analysis of unicellular organisms. J. Gravit. Physiol., 9:345-6.

TEIXEIRA, G.A., GEREMIAS, R., PICH, C.T., SCHOENFELDER, T., ÁVILA JUNIOR, S., PEDROSA, R.C., DIEDRICH, R. \& MACAN, J.M., 2004, Avaliação da toxicidade de efluentes mineração de carvão, utilizando-se parâmetros físico-químicos e teste cometa em Allium cepa L. In: XIX Reunião Anual da Federação de Sociedade de Biologia. Águas de Lindóia/SP. Caderno de Resumos.

TALLINI, K., GUIMARÃES, L.S.P., FACHEL, J.M.G. \& RODRIGUEZ, M.T.R., 2012, Estabelecimento de Protocolo de Avaliação de Risco Ecológico em Ambiente Aquático tendo o Programa de Monitoramento do Rio Jacuí, São Jerônimo (RS). J. Braz. Soc. Ecotoxicol., 7:55-63. http://dx.doi.org/doi:10.5132/ jbse.2012.01.009.

XIANLIANG, Y.I., SUNG-WOOK, K. \& JINHO, J., 2010, Longterm evaluation of lethal and sublethal toxicity of industrial effluents using Daphnia magna and Moina macrocopa. J Hazard Mater., 178:982-987. http://dx.doi.org/doi:10.1016/j. jhazmat.2010.02.034. 